\title{
Calibration and Performance Evaluation of an UNCOOLED INFRARED THERMOGRAPHIC SYSTEM
}

\author{
Sara Rainieri, Fabio Bozzoli and Giorgio Pagliarini \\ Department of Industrial Engineering - University of Parma \\ Parco area delle Scienze 181/A 43100 Parma - Italy \\ Fax+390521905701 \\ e-mal:sara.rainieri@unipr.it
}

\begin{abstract}
The efforts made in the last decay in the field of infrared detectors technology are mainly devoted to the development of systems of high sensitivity and performance characterized, at the same time, by low cost and simple maintenance. These goals are hardly achieved with photon detectors which, in spite of the high sensitivity and signal-to-noise performance, need to be cooled in order to operate correctly. Therefore they are often integrated in heavy and expensive instruments because of the cryogenic or thermoelectric cooling device required. For this reason, a big revolution has been achieved with the development of uncooled IR arrays, like the thermistor bolometer which is nowadays applied in most of infrared system available on the market [1]. Until the nineties this kind of thermal detector had not been exploited extensively neither in civil nor in military applications since its performance was believed to be rather poor in terms of sensitivity, time response and stability. The possibility to operate at room temperature and to offer low cost thermographic systems has instead acted as a stimulus for the applied research in this field to expend vigorous effort in order to develop new strategies to compensate the disadvantages of this kind of infrared detector. The market of infrared cameras has followed this trend, by offering as main product low-cost instruments based on the microboleter IR detector technology. The production of instruments based on the mature technology of cooled photon IR detector has instead been limited and directed to a specific market sector (mainly military or research) by causing a significant rise in their cost. This aspect may represent a problem for many research laboratories which may encounter some difficulties in purchasing high sensitivity and performance instruments. The object of the investigation here presented is to consider these aspects by means of an experimental analysis aimed to the assessment of the performance of an infrared camera having a $160 \times 120$ array of microbolemetric detector. The potential capability of the instrument have been verified by means of measurements taken by observing an isothermal plate of uniform emissivity in the temperaure range $10-80^{\circ} \mathrm{C}$. Some representative results regarding the data acquired by viewing the plate kept at a uniform temperature of $40^{\circ} \mathrm{C}$ are shown in figure 1 . The frequency histogram of the signal is reported both for a single image and for the image obtained by averaging 200 images acquired at a frequency of $50 \mathrm{~Hz}$. The response of a single pixel in instead reported as function of time in figure 2.
\end{abstract}

The application field to which the instrument performance test is addressed is quantitative measurements in the field of heat transfer. In particular the measurements are intended for anpplication of the infrared system to the estimation of the local heat transfer coefficient on thin surfaces. Regarding this specific field, Rainieri et al. [2-3] have successfully developed an optimal data processing procedure, based on the Wiener filter technique, to be applied to infrared thermographic temperature maps in order to recover the heat transfer coefficient distribution on thin metallic surfaces. In this experimental investigation these Authors use an infrared camera, having a Focal Plane Array of photoemissive PtSi detectors working in the 3-5 nm spectral range and cooled to a temperature of $77 \mathrm{~K}$ by a Stirling cycle incorporated in the instrument, namely the PRISM DS infrared camera by Flir Systems. The same Authors have proved that a basic step in order to apply successfully the infrared thermographich technique to this specific research field, and in general in 
quantitative application in the heat transfer research filed, is an accurate calibration of the detectors' array to be possibly made in situ [4-6]. The object of the investigation here presented is to test the capability of a new technology uncooled infrared microbolometric detectors (namely the ThermoVision A20-M by Flir Systems), in terms of signal to noise ratio, sensors' stability and uniformity, and to compare it with the performance achieved with the cooled Focal Plane Array infrared camera in the above referenced investigation.

The main outcome is an adequate instrument's calibration and signal processing procedure for quantitative measurements in heat transfer application.
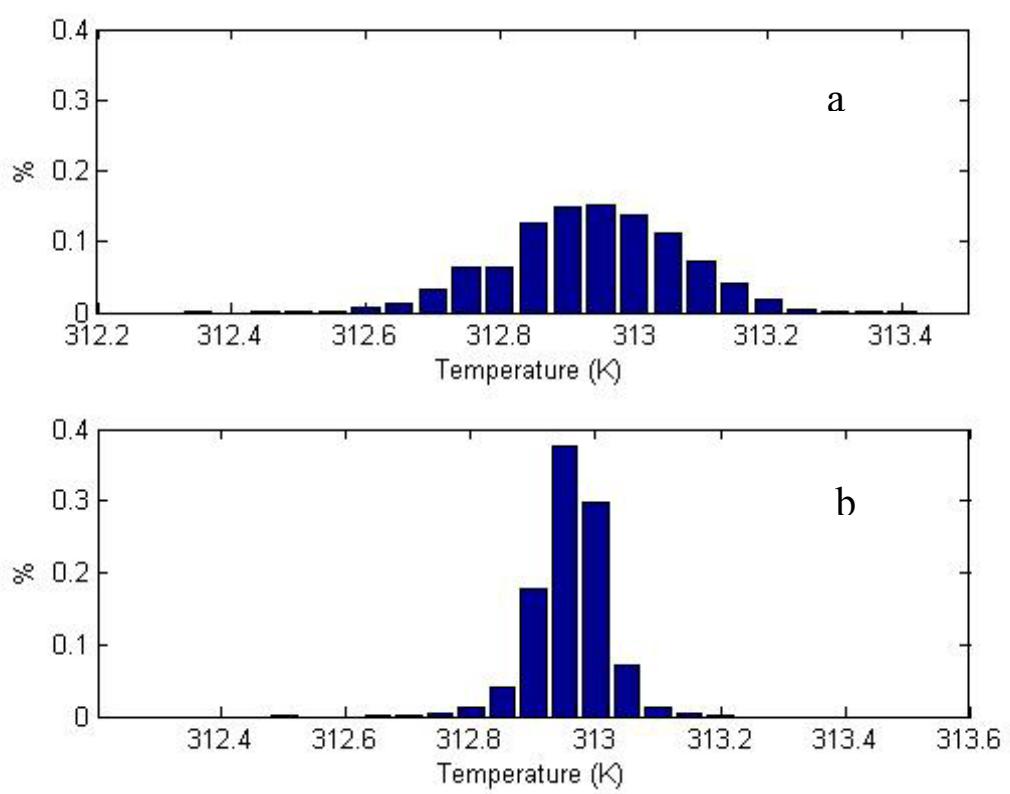

Figure 1: Frequency histogram of the signal: a) signal of a single image b) signal averaged over 200 images

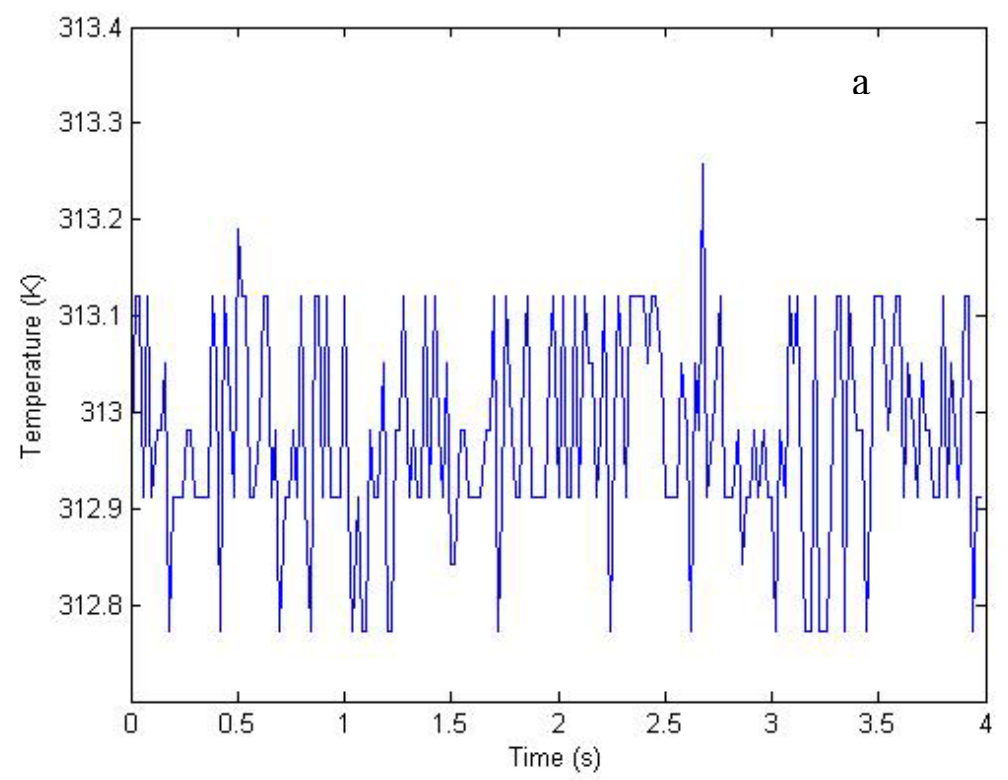

Figure 2: Response of a single pixel versus time 


\section{BIBLIOGRAPHIC REFERENCES}

1. Rogalski A., "Infrared detectors: an overview", Infrared Physics and Technology, Vol. 43, pp.187-210, 2002.

2. Rainieri S. and Pagliarini G., "Data Filtering Applied to Infrared Thermographic Measurements Intended for the Estimation of Local Heat Transfer Coefficient", Experimental Thermal and Fluid Science, Vol. 26, pp.109-114, 2002.

3. Rainieri S., Bozzoli F. and Pagliarini G., "Wiener Filtering Technique Applied to Thermographic Data Reduction Intended for the Estimation of Plate Fins Performance", Experimental Thermal and Fluid Science, Vol. 28, Issue 2-3, pp.179-183, 2004.

4. Rainieri S. and Pagliarini G., "Calibrazione di un Termografo a Matrice di Sensori per Applicazioni nel Settore dello Scambio Termico", Atti del XVI Congresso Nazionale sulla Trasmissione del Calore, Siena 18-19 Giugno 1998, Vol. 2, pp.795-806, 1998.

5. Rainieri S. and Pagliarini G., "Data Processing Technique Applied to the Calibration of a High Performance FPA Infrared Camera", Infrared Physics and Technology, Vol. 43, Issue 6, pp. 345-351, 2002.

6. Rainieri S. and Pagliarini G. "Thermographic Image Processing Intended for the Estimation of Local Heat Transfer Coefficient in Channel Flow Configuration”, Proc. 4th European Thermal Science Conference, Birmingham 2004. 